\title{
INVESTIGAÇÃO DA VIOLÊNCIA DE GÊNERO NA AMÉRICA LATINA E CARIBE: PEQUENA REVISÃO DA LITERATURA (2017-2019)
}

\author{
INVESTIGACION DE LA VIOLENCIA DE GÉNERO EN AMÉRICA LATINA Y EL \\ CARIBE: UNA BREVE REVISIÓN DE LITERATURA (2017-2019)
}

\author{
INVESTIGATING GENDER VIOLENCE IN LATIN AMERICA AND THE \\ CARIBBEAN: A SMALL LITERATURE REVIEW (2017-2019)
}

\author{
Solange Aparecida de Souza MONTEIRO ${ }^{1}$ \\ Claudionor Renato da SILVA ${ }^{2}$ \\ Paulo Rennes Marçal RIBEIRO ${ }^{3}$
}

RESUMO: A violência de gênero assume importante espaço de produção de conhecimento para a área da Educação Sexual, principalmente quando inserimos estes estudos em contextos educativos que se voltam para um currículo para a escola de educação básica e ensino superior, para ações em espaços sociais como os coletivos dos movimentos sociais, partidos políticos e frentes de empoderamento feminino, espaços estes que podem desenvolver lutas contra o feminicídio e as diversas violências sofridas pelas mulheres e outros grupos de gênero "não masculinos". A situação da violência de gênero se agrava em nosso atual estado de pandemia proporcionado pelo novo Corona Vírus, que obrigando a sociedade ao isolamento social, fez com que casais e famílias passassem muito mais momentos juntos, fator desencadeador do aumento da violência contra a mulher. Estas alterações no modo de vida das famílias revelam a importância de estudos na área da Educação Sexual neste tema. Optamos, portanto, em fazer um levantamento acerca dos estudos publicados nos últimos três anos e divulgados no Google Acadêmico, cuja descrição e análise fornecessem elementos que pudessem desencadear uma discussão sobre a violência de gênero na América Latina e Caribe entre pesquisadores e profissionais que atuam com Educação Sexual. construindo um encaminhamento de pesquisas na temática no campo da Educação Sexual a partir das tendências dos estudos dos últimos três anos. Verificamos que há poucos estudos publicados, especificamente sobre o Caribe, aspecto que sugere a necessidade de ampliação do espaço investigativo e do investimento em pesquisas sobre violência de gênero.

PALAVRAS-CHAVE: Violência de gênero. Educação sexual. América latina. Caribe.

RESUMEN: La violencia de género supone un espacio importante para la producción de conocimientos para el área de Educación Sexual, especialmente cuando insertamos estos estudios en contextos educativos que recurren a un currículo para la escuela de educación

${ }^{1}$ Universidade Estadual Paulista (UNESP), Araraquara - SP - Brasil. Doutoranda em Educação Escolar na UNESP. Mestre em Processos de Ensino, Gestão e Inovação. ORCID: http://orcid.org/0000-0002-1640-0266 Email: solmonteiro@ifsp.edu.br

${ }^{2}$ Universidade Federal de Jataí (UFJ), Jataí - GO - Brasil. Professor Adjunto. Doutor em Educação Escolar. ORCID: https://orcid.org/0000-0003-1693-4804. E-mail: claudionorsil@gmail.com

${ }^{3}$ Universidade Estadual Paulista (UNESP), Araraquara - SP - Brasil. Professor Associado no Departamento de Psicologia da Educação e no Mestrado em Educação Sexual. Doutor em Saúde Mental e Livre-Docente em Sexologia e Educação Sexual. ORCID: http://orcid.org/0000-0002-1552-5702. E-mail: paulo.rennes@unesp.br

RPGE- Revista on line de Política e Gestão Educacional, Araraquara, v. 24, n. 2, p. 649-667, maio/ago., 2020. e-ISSN:1519-9029. 
básica y educación superior, para acciones en espacios sociales como los colectivos de movimientos sociales, partidos políticos y frentes de empoderamiento de las mujeres, espacios que pueden desarrollar luchas contra el feminicidio y las diversas violencias sufridas por mujeres y otros grupos de género "no los hombres. La situación de violencia de género empeora en nuestro estado actual de pandemia proporcionado por el nuevo Virus Corona, que obliga a la sociedad al aislamiento social, hizo que las parejas y las familias pasaran muchos más momentos juntos, un factor que desencadena el aumento de la violencia contra las mujeres. Estos cambios en el modo de vida de las familias revelan la importancia de los estudios en el área de la Educación Sexual en este tema. Por lo tanto, elegimos hacer una encuesta sobre los estudios publicados en los últimos tres años y publicados en Google Scholar, cuya descripción y análisis proporcionaban elementos que podrían desencadenar una discusión sobre la violencia de género en América Latina y el Caribe entre investigadores y profesionales que trabajan con Educación Sexual. la construcción de una referencia de investigación sobre el tema en el campo de la educación sexual a partir de las tendencias de los estudios de los últimos tres años. Encontramos que hay pocos estudios publicados, específicamente sobre el Caribe, un aspecto que sugiere la necesidad de ampliar el espacio de investigación e invertir en investigación sobre violencia de género.

PALABRAS CLAVE: Violencia de género. Educación sexual. Latinoamérica. Caribe.

ABSTRACT: Gender violence assumes an important space for the production of knowledge for the area of Sexual Education, especially when we insert these studies in educational contexts that focus on a curriculum for the school of basic education and higher education, for actions in social spaces such as collectives social movements, political parties and women's empowerment fronts, spaces that can develop fights against feminicide and the various violence suffered by women and other "non-male" gender groups. The situation of gender violence is aggravated in our current pandemic state brought about by the new Corona Virus, which forcing society to social isolation, made couples and families spend many more moments together, a triggering factor for the increase in violence against women. These changes in the families' way of life reveal the importance of studies in the area of Sexual Education about this subject. We therefore chose to survey the studies published in the last three years and publicized on Google Scholar, whose description and analysis would provide elements that could trigger a discussion on gender violence in Latin America and the Caribbean between researchers and professionals who work with Sexual Education. Building a direction of research on the theme in the field of Sexual Education from the trends of studies of the last three years. We found that there are few published studies, specifically on the Caribbean, an aspect that suggests the need to expand the investigative space and invest in research on gender violence.

KEYWORDS: Gender violence. Sexual education. Latin america. The caribbean.

\section{Introdução}

A problemática desta pesquisa está assim definida: a partir das publicações dos últimos três anos (2017-2019) sobre a violência de gênero na América Latina (AL) e Caribe (CA) quais as tendências de estudos para a área da Educação Sexual nesta temática? Os estudos sobre a violência de gênero nessa macrorregião encontram certa dificuldade de empreendimento 
intelectual, no sentido da organização de referenciais teóricos que não estejam somente em periódicos ou, como assim está, em discussão com bases em dados estatísticos, como os mapas da violência da CEPAL (Comissão Econômica para a América Latina e Caribe), ligada às Nações Unidas e, para o caso brasileiro, para citar apenas um exemplo de publicação, o "Mapa da Violência de 2015: homicídio de mulheres no Brasil” (WAISELFISZ, 2015).

A produção sobre violência de gênero na América Latina e Caribe é predominantemente em língua espanhola, como Arnold (1997) e Aponte Sanches (2008). No Brasil podemos mencionar Pereira (2014), Di Piero et al., (2019), Teles e Melo (2002) e Castro e Riquer (2002). Lima e Colombo (2019) estudam o feminismo negro e fazem um recorte sobre a questão do racismo "que ainda permeia a sociedade [e] faz das mulheres negras alvo de múltiplas subordinações, ignoradas pelas agendas feministas por décadas" (p. 182) e é elemento reforçador da violência que se perpetua contra a mulher negra. Di Piero et al., (2019, p. 14) apontam que

os avanços com relação ao acesso à educação na América Latina e Caribe são expressivos: 5 dos 24 países da região - Barbados, Cuba, Bahamas, Jamaica e Brasil - erradicaram a desigualdade de gênero com relação ao acesso educacional. Em 2006 o Brasil estava na $74^{a}$ posição nesse subitem e passou para $1^{\mathrm{a}}$ em 2017.

Citando autores como Schwab (2017), Bárcena (2010) e Alves e Corrêa (2009), Di Piro et al., (2019, p. 13-14) destacam a "adoção de marcos legais igualitários, a construção e o fortalecimento de mecanismos para o desenvolvimento das mulheres e sanções de leis contra a violência de gênero", assim como "o empoderamento das mulheres e os avanços legislativos e de políticas públicas".

Marques, Barbosa e Hutz (2010) estudaram a participação da mulher nas sociedades da América Latina e no Caribe no período compreendido por 1990 a 2010, destacando sua inserção no trabalho, nas famílias e nas comunidades, inclusive analisando a violência e a participação feminina no poder legislativo.

Em 2013, no XXVII Simpósio Nacional de História, foi apresentado um trabalho sobre as leis de combate a violência contra a mulher na América Latina. Nesse trabalho, Souza (2013, p. 6) historiou "a violência contra a mulher, com destaque para o feminicídio, [que] possui elevados índices e um padrão de impunidade frente aos crimes cometidos contra as mulheres". A autora descreve as leis para combater a violência contra a mulher

Pela questão do feminicídio se tornar um problema de saúde pública, até a OMS (OMS, 2013) tem se tornado atenta à luta contra a violência de gênero em todas as partes do mundo. 
As Nações Unidas (ONU) também assumiram a questão. Ambas, CEPAL e ONU não apenas divulgam dados e estimulam Observatórios nos países da AL e CA, como também, publicam obras encomendadas a pesquisadores(as) especialistas no tema "Mulheres" e a abrangência do tema da violência de gênero e toda a sua amplitude conceitual. Dois exemplos dessas publicações são a ONU Mulheres (2016) e a ONU Mujeres (2012). No Brasil, o OBSERVA, ligado à UFBA - Universidade Federal da Bahia, mantém o Observatório da Lei Maria da Penha, com publicações importantes como o Observe (2010).

Em 2017 há o destaque de uma produção da FLACSO (Facultad Latinoamericana de Ciencias Sociales) do Chile, de autoria de Guajardo Soto e Cenitagoya Garín (2017). Nesta obra se destacam assuntos importantes referentes ao feminicídio e suicídio de mulheres na América Latina e no Caribe. Excelente fonte para um referencial teórico sobre a violência de gênero com enfoque nos seguintes temas gerais: prevenção e ações contra violência de gênero; políticas nacionais nos países da macrorregião referentes à violência de gênero; o referencial da dominação patriarcal para fundamentar a contemporaneidade da violência contra mulheres, principalmente; algumas práticas da Cooperación Sur-Sur e implementações políticas contra a violência de gênero.

A CEPAL possui várias publicações sobre a violência de gênero, com destaque ao tema da "equidade de gênero". A última é de 2019 sob o título "La autonomia de las mujeres em escenarios económicos cambiantes" (CEPAL, 2019), um importante referencial para a construção de um histórico da violência de gênero na AL e CA.

A ONU, desde 2010 possui um órgão que trata da igualdade de gênero e empoderamento das meninas e mulheres. Conhecido como “ONU Mulheres” este órgão já possui muitas publicações no Brasil, como "Diretrizes Nacionais Feminicídio" (BRASIL, 2016) que estabelece protocolos de violência de gênero e destaca alguns conceitos e interseccionalidades de gênero: classe, geracionalidade, deficiências, raça e cor, e etnia. Os estudos sobre violência de gênero têm sido marcados na América Latina e Caribe pela quantificação de casos e por textos de enfrentamento e defesa por políticas governamentais e, quando da existência destas políticas, a denúncia e a resistência. A relevância destes estudos que motivam os autores deste artigo é que, diante da pandemia do novo Corona vírus, casos de violência contra mulheres e feminicídio tendem a aumentar, dado que as pessoas estão em quarentena em suas casas.

Esta maneira de tratar o tema, a partir dos dados estatísticos e seus mapas, bem como o referencial nos estudos sobre gênero, sem dúvida é uma forma de expor o tema da violência de gênero no âmbito de uma defesa que se faz neste trabalho, que é a defesa por uma Educação Sexual emancipatória, justificada na cientificidade histórica, e necessária no empoderamento 
da mulher e para a formulação de políticas públicas mais amplas, tanto universitárias quanto sociais, com apoio e participação dos movimentos sociais, dos governos locais e nacionais, dos partidos políticos, etc.

Tomaremos como ponto de partida dos principais referenciais "oficiais" ou produzidos por órgãos internacionais latino-americanos e caribenhos sobre violência de Gênero, a publicação do livro "Los enfoques de género en las universidades" elaborado pelo Comité Académico Género da AUGM - Asociación de Universidades Grupo Montevideo (ROJO; JARDON, 2018).

A segunda parte da obra trata diretamente da violência de gênero na universidade, apontando, algumas indicações de enfrentamento do problema: 1) uma Educação Sexual que enfoque gênero; 2) propostas de políticas universitárias de enfrentamento; 3) pesquisas que evidenciem a violência(s) e promovam cidadania, ou seja, cujos resultados modifiquem a realidade, logo, investigações que transformem desafios e medos em maior liberdade para denúncias e punições, eliminando a violência em todas as suas formas para que se evitem os atuais quadros de depressão entre universitários(as), sobretudo e principalmente mulheres, e para não se chegar aos casos mais extremos de abandono do curso e até ao suicídio.

Mas que autores(as) dão base para estas discussões na AUGM? Como apontado no "sinal de alerta" sobre estes "achados", grande parte dos autores, discutem gênero especificamente em Judith Butler (BUTLER, 1993), um dos poucos referenciais encontrados. No restante do levantamento, o que encontramos são obras (livros) que tratam quase exclusivamente de dados da violência de gênero com estatísticas nos países da macrorregião. No Brasil, uma autora que aparece bastante enquanto referencial é Heleieth Iara Bongiovani Saffioti (SAFFIOTI, 2004).

No Brasil, em 2013, o Ministério da Saúde também produziu um guia de orientações sobre o papel do SUS (Sistema Único de Saúde) diante da problemática da migração, considerando as mulheres cubanas e venezuelanas, principalmente, que começaram a chegar ao Brasil logo na passagem para a primeira década dos anos 2000 (BRASIL, 2013).

$\mathrm{O}$ que se conclui sobre os principais referenciais contemporâneos considerados aqui "oficiais-internacionais" e também locais? Primeiro: não há uma referência ampla que atenda a especificidade do tema, no âmbito da América Latina e Caribe. Uma segunda colocação, na forma de várias perguntas para estimular a pesquisa histórica e científica da violência de gênero na América Latina e Caribe na área da Educação Sexual: os referenciais existentes nos permitem uma construção histórica da violência de gênero na região e, no caso específico, um histórico e uma cientificidade epistemológica da violência de gênero no Brasil? Em seu 
conjunto, as pesquisas e a produção de conhecimento, já efetivadas e com forte tendência aos dados estatísticos e mapeamentos, de um lado, e a denúncia e enfrentamento político, de outro, podem contribuir para a construção de um referencial sólido e que se consolide para os estudos sobre a violência de gênero em todas as suas frentes temáticas, não só interseccionais, mas também, a violência de gênero institucional, a violência de gênero doméstica, a violência de gênero política, etc.?

São desses quadros de produção e de políticas internacionais, nacionais e iniciativas de universidades e movimentos sociais mais amplos que se discursa sobre a violência de gênero nesta pesquisa. Ressaltamos a importância de referenciais teóricos sistematizados e a ênfase na violência contra as mulheres sem deixar de lado outros segmentos de gênero, duas questões que fazem parte dos conteúdos a serem trabalhados na Educação Sexual. Assim, efetivamos a busca de referenciais teóricos mais consolidados nestas discussões visando encontrar autores(as) que, em cada país da América Latina e Caribe, se debruçam e produzem sobre o tema.

A Revisão da Literatura proposta foi realizada a partir de Sampieri, Collado e Lúcio (2006) por meio de uma pesquisa bibliográfica feita no Google Acadêmico, utilizando-se o descritor composto "violência de gênero; América Latina e Caribe”, no período de 2017 a 2019. Os trabalhos identificados foram elencados, registrados, selecionados, lidos e separados por ano de publicação, formando a composição analítica de propostas de tendências de pesquisas em violência de gênero na macrorregião da América Latina e Caribe.

Antes da apresentação dos resultados e as discussões geradas para construção das tendências, são válidas algumas considerações sobre: 1) a importância dos estudos latinoamericanos e caribenhos na área da Educação e da Educação Sexual; 2) local desta macrorregião.

No tópico 1, a região conta com atenção total pela CEPAL e outros órgãos internacionais, principalmente nas temáticas sociais, políticas e econômicas. Grande parte desta atenção, em estudos e políticas, se deve às desigualdades sociais, o descaso às populações indígenas, desgoverno com ausência de políticas de sustentabilidade, inclusão e proteção social. Um importante documento sobre esses estudos e a relevância da macrorregião nas pesquisas das ciências humanas e sociais foi recentemente lançado pela CEPAL (CEPAL, 2020).

Em relação à macrorregião mencionada como tópico 2, vale recordar que a expressão América Latina foi utilizada pela primeira vez por Francisco Bilbao, em 1856. Na América Latina e Caribe convivem vários idiomas oficiais: o espanhol, na maioria; o francês (no Haiti e na Guiana Francesa); e o português (apenas no Brasil). Há ainda o Caribe anglófono (antigamente denominado Antilhas Britânicas) e o inglês é falado em Belize, Jamaica, 
Bahamas, Trinidad e Tobago, Antígua e Barbuda, Santa Lúcia, Barbados. No Suriname o idioma oficial é o holandês e na Guiana o inglês, ambos localizados na América do Sul mas sem fazer parte da América Latina. O Caribe é formado por um conjunto de ilhas e Estados insulares no Mar do Caribe.

\section{As produções do triênio 2017-2018-2019}

Os quadros a seguir, enumerados de 1 a 3, apresentam as produções sob os descritores já explicados no final da seção anterior.

Nos primeiros cem trabalhos verificados, não foi possível alcançar o que a metodologia bibliográfica chama de "saturação dos dados" (SAMPIERI; COLLADO; LÚCIO, 2006), ou seja, quando os temas se repetem, sejam títulos, palavras-chave, temáticas. Mas isso não impediu de serem construídas, pelo menos, cinco tendências para os estudos da área da Educação Sexual no tema da violência de gênero. Por outro lado, indica que a temática é ampla com vários recortes e, portanto, se pode inferir que há muitas frentes de estudos apenas iniciados ou uma única vez tratados, necessitando, assim, de aprofundamentos e novos encaminhamentos.

O primeiro quadro apresenta parte dos estudos elencados de 2017, o que auxilia a demarcação das tendências dos estudos para fomentar pesquisas na área da Educação Sexual em toda a macrorregião latino-americana e caribenha.

Quadro 1 - Levantamento das produções de pesquisas em 2017

\begin{tabular}{|c|c|c|c|}
\hline REFERÊNCIA & $\begin{array}{l}\text { CITA } \\
\text { ÇÕES }\end{array}$ & $\begin{array}{l}\text { PALAVRAS- } \\
\text { CHAVE }\end{array}$ & DESCRIÇÃO BREVE \\
\hline $\begin{array}{l}\text { IBÁÑEZ, D. B. La } \\
\text { violencia de género em } \\
\text { Ecuador: um estúdio } \\
\text { sobre los universitários. } \\
\text { Revista Estudos } \\
\text { Feministas, } \\
\text { Florianópolis, SC, v. } 25 \text {, } \\
\text { n.3, set./dez. } 2017 .\end{array}$ & 22 & $\begin{array}{l}\text { Violencia de } \\
\text { género. } \\
\text { Ecuador. } \\
\text { Imaginario } \\
\text { andino. }\end{array}$ & $\begin{array}{l}\text { Há um histórico social e cultural, bem } \\
\text { como político que justificam os altos } \\
\text { índices de violência nos países latino- } \\
\text { americanos, um dos mais altos do } \\
\text { mundo. Formula-se no artigo um } \\
\text { "imaginário" da violência na cultura } \\
\text { andina. A violência é comparada a } \\
\text { uma epidemia social. }\end{array}$ \\
\hline $\begin{array}{l}\text { OZERIN, I. P. Acción } \\
\text { colectiva de las mujeres y } \\
\text { procesos emancipadores } \\
\text { em América Latina y el } \\
\text { Caribe. Una aproximación } \\
\text { desde los casos de Cuba, } \\
\text { Bolivia y Ecuador. Foro } \\
\text { Internacional, México, v. } \\
\text { 57, n. 4, out./dez. } 2017 .\end{array}$ & 7 & $\begin{array}{l}\text { Acción coletiva de } \\
\text { las mujeres. } \\
\text { Política de género. } \\
\text { América Latina y } \\
\text { el Caribe. } \\
\text { Revolución } \\
\text { Cubana. } \\
\text { Procesos } \\
\text { constituyentes. }\end{array}$ & $\begin{array}{l}\text { Enfoque no movimento de mulheres e } \\
\text { processos coletivos de participação } \\
\text { social. Destaca a Revolução Cubana e } \\
\text { as experiências das lutas das mulheres } \\
\text { na Bolívia e no Equador, experiências } \\
\text { recentes. }\end{array}$ \\
\hline
\end{tabular}




\begin{tabular}{|c|c|c|c|}
\hline $\begin{array}{l}\text { SALGADO, A. B. B. } \\
\text { Feminicídio na América } \\
\text { Latina e a discussão da } \\
\text { eficácia do tratamento } \\
\text { penal da violência contra } \\
\text { a mulher. In: } \\
\text { CONGRESSO ALAS, } \\
\text { 31., 2017, Montevideo. } \\
\text { Anais [...]. Montevideo, } \\
\text { Uruguay, } 3 \text { a } 8 \text { de dez. } \\
2017 \text {. }\end{array}$ & - & $\begin{array}{l}\text { Feminicídio. } \\
\text { Gênero. } \\
\text { Direito. } \\
\text { Penal. }\end{array}$ & $\begin{array}{l}\text { A morte de mulheres é focada a partir } \\
\text { de dados da CEPAL de } 2016 \text {. }\end{array}$ \\
\hline $\begin{array}{l}\text { ARANDA, T. J. C.; } \\
\text { FINES, M. B.; DUETTE, } \\
\text { V.V. Los estudiantes } \\
\text { universiversitarios ante la } \\
\text { violencia de género. } \\
\text { Feminismo/s, p. 45-70, } \\
29 \text { jun. } 2017 \text {. }\end{array}$ & 1 & $\begin{array}{l}\text { Género. } \\
\text { Violência. } \\
\text { Igualdad. } \\
\text { Estudiantes. } \\
\text { Universidad. }\end{array}$ & $\begin{array}{l}\text { A pesquisa investiga as crenças sobre } \\
\text { igualdade e violência de gênero de } \\
\text { estudantes paraguaios numa } \\
\text { Universidade, a Universidad Nacional } \\
\text { del Este. }\end{array}$ \\
\hline $\begin{array}{l}\text { TERESI, V. M. La } \\
\text { violencia de género em } \\
\text { Brasil: um balance de la } \\
\text { Ley "Maira da Penha" } \\
\text { (2006-2016). Revista } \\
\text { CIDOB d'Afers } \\
\text { Internacionals, n. 117, p. } \\
\text { 101-122, 2017. }\end{array}$ & 3 & $\begin{array}{l}\text { Brasil. } \\
\text { Violencia de } \\
\text { género. } \\
\text { Ley "Maria da } \\
\text { Penha". } \\
\text { Politicas públicas. }\end{array}$ & $\begin{array}{l}\text { O balanço dos } 10 \text { anos analisa os casos } \\
\text { tratados pelo país no enfrentamento da } \\
\text { violência contra mulheres. }\end{array}$ \\
\hline $\begin{array}{l}\text { TONELLI, M. J. F.; } \\
\text { BEIRAS, A.; RIED, J. } \\
\text { Homens autores de } \\
\text { violência contra mulheres: } \\
\text { políticas públicas, } \\
\text { desafios e intervenções } \\
\text { possíveis na América } \\
\text { Latina e Portugal. } \\
\text { Florianópolis: Revista de } \\
\text { Ciências Humanas, v. } \\
\text { 51, n. 1, p. 174-193, } 2017 .\end{array}$ & 6 & $\begin{array}{l}\text { Violência de } \\
\text { gênero. } \\
\text { Programas de } \\
\text { atendimento a } \\
\text { homens. Políticas } \\
\text { públicas. }\end{array}$ & $\begin{array}{l}\text { Mapeamento de programas para } \\
\text { homens autores de violência contra } \\
\text { mulheres. }\end{array}$ \\
\hline
\end{tabular}

Fonte: elaborado na pesquisa

No levantamento de produções de 2017 verificamos que a violência contra as mulheres é diversa e envolve multiplicidade étnica, cultural, linguística e sexual. Entre as estratégias mais urgentes para sua erradicação, recomenda-se às agências governamentais a intensificação de campanhas e estratégias que transformem o imaginário sobre a violência, particularmente de crianças e adolescentes que têm reações e atitudes mais pobres e limitantes, mas também de jovens mais velhos e adultos. A violência contra a mulher se relaciona a uma condição de poder e, embora a porcentagem de ataques provocados por mulheres não seja baixa, os principais agressores são os homens. No caso do Brasil, o Ministério Público desempenha um papel relevante para assegurar a efetividade da Lei Maria da Penha e há uma atuação eficiente dos 
promotores de justiça, mas ainda persistem deficiências a serem superadas, na medida em que outras esferas do sistema de justiça e de segurança ainda são influenciadas por estruturas machistas. É essencial a incorporação de ações mais efetivas, como os Programas de Atenção a Homens Autores de Violência Contra as Mulheres, assim como fortalecer procedimentos na perspectiva da igualdade de gênero e de direitos. São aportes que favorecem o enfrentamento da violência contra as mulheres e meninas, fortalecendo a rede de combate e prevenção.

A seguir o levantamento dos estudos em 2018:

Quadro 2 - Levantamento das produções de pesquisas em 2018

\begin{tabular}{|c|c|c|c|}
\hline REFERÊNCIA & $\begin{array}{l}\text { CITA } \\
\text { ÇÕES }\end{array}$ & $\begin{array}{l}\text { PALAVRAS- } \\
\text { CHAVE }\end{array}$ & DESCRIÇÃO BREVE \\
\hline $\begin{array}{l}\text { SILVA, C. R. Violência } \\
\text { de gênero no Brasil e na } \\
\text { América Latina: um } \\
\text { enfoque psicanalítico, a } \\
\text { produção de } \\
\text { conhecimento e } \\
\text { perspectivas de } \\
\text { enfrentamento. Doxa, v. } \\
\text { 20, n. 1, jan./jun. 2018. }\end{array}$ & - & $\begin{array}{l}\text { Violência de } \\
\text { Gênero. } \\
\text { Psicanálise. } \\
\text { Produção de } \\
\text { Conhecimento. } \\
\text { Enfrentamento } \\
\text {. }\end{array}$ & $\begin{array}{l}\text { Acrescenta-se à violência contra } \\
\text { mulheres, a violência contra } \\
\text { crianças, contra homossexuais e } \\
\text { outras diversidades, a partir da teoria } \\
\text { psicanalítica. Indica-se práticas de } \\
\text { enfrentamento por meio da Educação } \\
\text { Sexual. }\end{array}$ \\
\hline $\begin{array}{l}\text { ALBAINE, L. Estrategias } \\
\text { legales contra la violencia } \\
\text { politica de género. Las } \\
\text { oportunidades de acción. } \\
\text { La Ventana. Revista de } \\
\text { Estudios de Género, v. } 6 \text {, } \\
\text { n. } 48, \text { jul./dez. } 2018\end{array}$ & 1 & $\begin{array}{l}\text { Participación } \\
\text { política de las } \\
\text { mujeres. } \\
\text { Paridade de } \\
\text { género. } \\
\text { Violencia } \\
\text { política. } \\
\text { Estrategias } \\
\text { legales. } \\
\text { Paridad } \\
\text { sustantiva. } \\
\text { América } \\
\text { Latina. }\end{array}$ & $\begin{array}{l}\text { Investigações sobre políticas contra a } \\
\text { violência de gênero. Particularmente, } \\
\text { a paridade de gênero e a violência } \\
\text { política de gênero. }\end{array}$ \\
\hline $\begin{array}{l}\text { VILLA, E. N. R. M.; } \\
\text { MACHADO, B. A. } \\
\text { Territórios da violência de } \\
\text { gênero: normativa } \\
\text { internacional e os casos } \\
\text { "Campo Algodoeiro" } \\
\text { (México) - "Morro do } \\
\text { Garrote" (Brasil). Revista } \\
\text { de Direito Internacional, } \\
\text { v. 15, n. 2, 2018. }\end{array}$ & - & $\begin{array}{l}\text { Vida precária. } \\
\text { Gênero. } \\
\text { Feminicídio. } \\
\text { Investigação } \\
\text { policial. }\end{array}$ & $\begin{array}{l}\text { O estudo se concentra em casos de } \\
\text { assassinatos de mulheres, jovens e } \\
\text { adultas (mortes por gênero) } \\
\text { ocorridos na cidade de Juárez, no } \\
\text { México e em Castelo, no estado do } \\
\text { Piauí, no Brasil. Se compara a } \\
\text { violência de gênero nestes dois } \\
\text { casos. }\end{array}$ \\
\hline $\begin{array}{l}\text { GUIMARÃES, R. C. S. et } \\
\text { al. Impacto em la } \\
\text { autoestima de mujeres em } \\
\text { situación de violencia } \\
\text { doméstica atendidas em } \\
\text { Campina Grande, Brasil. }\end{array}$ & 3 & $\begin{array}{l}\text { Violência } \\
\text { contra a } \\
\text { mulher. } \\
\text { Autoimagem. }\end{array}$ & $\begin{array}{l}\text { A investigação na área da saúde } \\
\text { pretende analisar os efeitos na saúde } \\
\text { da mulher, sob o impacto da } \\
\text { violência sofrida, a violência } \\
\text { doméstica. }\end{array}$ \\
\hline
\end{tabular}

RPGE- Revista on line de Política e Gestão Educacional, Araraquara, v. 24, n. 2, p. 649-667, maio/ago., 2020. e-ISSN:1519-9029. 


\begin{tabular}{|l|l|l|l|}
\hline Revista Cuidarte, v. 9, n. & & $\begin{array}{l}\text { Avaliação do } \\
\text { impacto na } \\
\text { Saúde. }\end{array}$ & \\
\hline
\end{tabular}

Fonte: elaborado na pesquisa

No levantamento do ano de 2018, percebemos a utilização das expressões violência doméstica, violência contra mulheres e violência conjugal. Também aparece o assédio político e a violência política contra as mulheres, ações que para serem erradicadas é necessário estabelecer um desenho institucional para os marcos regulatórios - canais administrativos, constitucionais, criminais e até internacionais - visando o estabelecimento de sanções apropriadas para cada tipo de caso, especificando claramente o componente de gênero como a força motriz por trás desse tipo de crime. Outra situação apontada é o assassinato de mulheres ocorrido no âmbito doméstico, que para os autores é revelador de um poder moldado na perspectiva de gênero.

Além dos textos constantes no Quadro 2, ressaltamos que 2018 foi um ano com intensa produtividade na área objeto deste estudo. Citamos aqui o Seminário Esforços na Região da América Latina e do Caribe para promover a Igualdade de Gênero ${ }^{4}$, que contou com doze trabalhos apresentados. Destaca-se nesse ano a Declaração da III Conferência Regional de Educação Superior para a América Latina e o Caribe - CRES, publicada pela UNESCO 5 .

Outra obra importante no levantamento realizado é do Instituto Igarapé, o Artigo Estratégico 32, de março 2018, intitulado A agenda sobre mulheres, paz e segurança no contexto latino-americano: desafios e oportunidades (GIANNINI et al., 2018).

Trata-se de uma publicação dedicada à Marielle Franco em que as autoras discorrem sobre o contexto de violência contra mulheres na América Latina: do tema do tráfico de drogas, envolvendo mulheres, até comunidades indígenas do Mato Grosso, no Brasil, as autoras detalham os "crimes" de Estado produzidos em decorrência de leis frágeis e extremamente "cruéis" para com mulheres, reforçando a violência de gênero como algo "legalizado".

O Quadro 3 apresenta as produções elencadas em 2019:

${ }^{4}$ Disponível em: https://repositorio.enap.gov.br/handle/1/3415. Acesso em: 03 maio 2020.

${ }^{5}$ Disponível em: https://revistas.psi.unc.edu.ar/index.php/integracionyconocimiento/article/view/22650. Acesso em: 03 maio 2020. 
QUADRO 3 - Levantamento das produções de pesquisas em 2019

\begin{tabular}{|c|c|c|c|c|}
\hline & REFERÊNCIA & CITAÇÕES & $\begin{array}{l}\text { PALAVRAS- } \\
\text { CHAVE }\end{array}$ & DESCRIÇÃO BREVE \\
\hline 1 & $\begin{array}{l}\text { MARQUES, B. M. A } \\
\text { atuação do movimento } \\
\text { Ni Una Menos como } \\
\text { rede (feminista) de } \\
\text { ativismo transnacional } \\
\text { na luta contra a } \\
\text { violência de gênero na } \\
\text { Argentina (2014- } \\
\text { 2016). Fronteira, } \\
\text { Revista de Iniciação } \\
\text { Científica em } \\
\text { Relações } \\
\text { Internacionais, v. 18, } \\
\text { n. 35, 2019. }\end{array}$ & 1 & $\begin{array}{l}\text { Redes } \\
\text { feministas } \\
\text { transnacionais. } \\
\text { Ni una Menos. } \\
\text { América } \\
\text { Latina. } \\
\text { Violência de } \\
\text { Gênero. }\end{array}$ & $\begin{array}{l}\text { Se faz um resgate das RFT } \\
\text { (Redes Feministas } \\
\text { Transnacionais) que denunciam } \\
\text { violências contra mulheres. O } \\
\text { estudo tem como foco a RFT na } \\
\text { Argentina, Uruguai, México e } \\
\text { Chile entre os anos de } 2014 \text { a } \\
2016 \text { da campanha Ni uma } \\
\text { Menos! } \\
\text { Citam estudos de Margaret Keck } \\
\text { e Katrhryn Sikkink } \text { (redes de } \\
\text { ativismos transnacionais), bem } \\
\text { como Valentine Monghadam }{ }^{7} \text { e } \\
\text { Sonia Alvarez }{ }^{8} \text { (RFT). }\end{array}$ \\
\hline 2 & $\begin{array}{l}\text { SOARES, D. Z.; } \\
\text { CHARLES, C. J. N.; } \\
\text { CERQUEIRA, C. A. } \\
\text { X. Feminicídio no } \\
\text { Brasil: gênero de } \\
\text { quem mata e de quem } \\
\text { morre. In: } \\
\text { ENANPEGE, 13., } \\
\text { 2019, São Paulo. } \\
\text { Anais [...]. São Paulo, } \\
2 \text { a } 7 \text { set. } 2019 .\end{array}$ & - & $\begin{array}{l}\text { Feminicídio. } \\
\text { Gênero. } \\
\text { Violência. }\end{array}$ & $\begin{array}{l}\text { O feminicídio é o estágio } \\
\text { máximo da violência contra a } \\
\text { mulher. Neste estudo, as autoras } \\
\text { examinam o contexto social e } \\
\text { étnico das mulheres que morrem } \\
\text { e a correlação com os homens } \\
\text { agressores (quem são). }\end{array}$ \\
\hline 3 & $\begin{array}{l}\text { NERI, F. S. Política de } \\
\text { atención a mujeres em } \\
\text { situación de violencia: } \\
\text { um estúdio } \\
\text { exploratório em } \\
\text { Ciudad del Este y Foz } \\
\text { de Yguazú. Revista } \\
\text { MERCOSUL de } \\
\text { Políticas Sociales, v. } \\
\text { 3, p. 139-155, } 2019 \text {. }\end{array}$ & - & $\begin{array}{l}\text { Políticas } \\
\text { sociais. } \\
\text { Proteção } \\
\text { social. } \\
\text { Direitos } \\
\text { humanos. } \\
\text { Mulheres. }\end{array}$ & $\begin{array}{l}\text { Trata de políticas públicas de } \\
\text { atenção a mulheres em situação } \\
\text { de violência entre estas duas } \\
\text { cidades fronteiriças. }\end{array}$ \\
\hline 4 & $\begin{array}{l}\text { MONJE, F. R.; } \\
\text { FOLLE, M. Z. } \\
\text { Violencia de género } \\
\text { contra las mujeres en } \\
\text { América Latina: una } \\
\text { reflexión crítica en } \\
\text { torno a las agendas de } \\
\text { género en la } \\
\text { integración regional. }\end{array}$ & - & $\begin{array}{l}\text { Violencia de } \\
\text { género contra } \\
\text { las mujeres. } \\
\text { Agenda de } \\
\text { género. } \\
\text { MERCOSUR. } \\
\text { SICA. }\end{array}$ & $\begin{array}{l}\text { Os autores refletem sobre a } \\
\text { incorporação da agenda de } \\
\text { gênero nos processos de } \\
\text { integração regional da América } \\
\text { Latina, focada na violência } \\
\text { contra a mulher. Analisam dois } \\
\text { casos específicos: o Mercado } \\
\text { Comum do Sul e o Sistema de } \\
\text { Integração da América Central. }\end{array}$ \\
\hline
\end{tabular}

${ }^{6}$ SIKKINK, K.; KECK, M. E. Activists beyond borders: advocacy net works in international politics. Ithaca: Cornell University Press, 1998.

${ }^{7}$ MOGHADAM, V. (Org). The Oxford Handbook of Transnational Feminist Activism. Oxford: Ed. Oxford, 2015.

${ }^{8}$ ALVAREZ, S. E. Engajamentos Ambivalentes, Efeitos Paradoxais: Movimentos feminista e de mulheres na América Latina e/em/contra o desenvolvimento. Revista Feminismos, Bahia, n. 4, 2014.

RPGE- Revista on line de Política e Gestão Educacional, Araraquara, v. 24, n. 2, p. 649-667, maio/ago., 2020. e-ISSN:1519-9029. 


\begin{tabular}{|c|c|c|c|c|}
\hline & $\begin{array}{l}\text { Los casos de } \\
\text { MERCOSUR y SICA. } \\
\text { Revista Aportes para } \\
\text { la Integración } \\
\text { Latinoamericana, } \\
\text { Año XXV, n. 41, p. 1- } \\
22,2019 \text {. }\end{array}$ & & & $\begin{array}{l}\text { Estudam a legislação de seus } \\
\text { países membros para traçar } \\
\text { diretrizes finais visando } \\
\text { considerar e repensar novos } \\
\text { mecanismos para expandir e } \\
\text { fortalecer a luta contra a } \\
\text { violência de gênero. }\end{array}$ \\
\hline 5 & $\begin{array}{l}\text { LIMA, F. S.; } \\
\text { COLOMBO, M. A. } \\
\text { Pensamento } \\
\text { descolonial e } \\
\text { feminismo negro na } \\
\text { América Latina. Belo } \\
\text { Horizonte: Mentum, } \\
\text { v. 14, n. 1, p. 181-201, } \\
2019 \text {. }\end{array}$ & - & $\begin{array}{l}\text { América } \\
\text { Latina. } \\
\text { Feminismo. } \\
\text { Mulher negra. } \\
\text { Pensamento } \\
\text { descolonial. }\end{array}$ & $\begin{array}{l}\text { Os autores questionam o modelo } \\
\text { hegemônico do feminismo } \\
\text { tradicional, afirmando que esta } \\
\text { matriz teórica é insuficiente para } \\
\text { garantir os direitos das mulheres } \\
\text { negras, não as representando. O } \\
\text { artigo estuda o feminismo a } \\
\text { partir da perspectiva do } \\
\text { pensamento descolonial. }\end{array}$ \\
\hline 6 & $\begin{array}{l}\text { MEJÍA, M. C.; } \\
\text { OCHOA, D.; RÍOS, P. } \\
\text { A.; YALEUMA, L. P.; } \\
\text { VELOZ, S. P. Factores } \\
\text { de riesgo e indicadores } \\
\text { de violencia de género } \\
\text { en mujeres socias de } \\
\text { bancos comunitarios } \\
\text { en Chimborazo. } \\
\text { Ecuador. Revista } \\
\text { Espacios, v. 40, n. 32, } \\
\text { p. 23-31, 2019. }\end{array}$ & 1 & $\begin{array}{l}\text { Factores de } \\
\text { riesgo. } \\
\text { Violencia de } \\
\text { género. } \\
\text { Mujeres. } \\
\text { Bancos } \\
\text { comunitários. }\end{array}$ & $\begin{array}{l}\text { Investigação da presença de } \\
\text { fatores de risco e indicadores de } \\
\text { violência de gênero em mulheres } \\
\text { de Chimborazo, Equador. } \\
\text { Verificou-se a existência de } \\
\text { papéis bem demarcados que } \\
\text { diferenciam homens e mulheres, } \\
\text { no entanto } 80 \% \text { das mulheres da } \\
\text { pesquisa relataram nunca ter } \\
\text { sofrido violência ou maus tratos. }\end{array}$ \\
\hline 7 & $\begin{array}{l}\text { COS-MONTIEL, F. } \\
\text { Eliminar la violencia } \\
\text { contra las mujeres en } \\
\text { América Latina y el } \\
\text { Caribe: objetivo } \\
\text { imprescindible para el } \\
\text { desarrollo sostenible, } \\
\text { la igualdad y la paz. } \\
\text { Madrid: Fundación } \\
\text { Carolina, Análisis } \\
\text { Carolina, v. 19, p. 1- } \\
\text { 13, 2019. }\end{array}$ & - & - & $\begin{array}{l}\text { O autor parte do compromisso } \\
\text { que os países têm com a Agenda } \\
2030 \text { para o Desenvolvimento } \\
\text { Sustentável da ONU, } \\
\text { discorrendo sobre a eliminação } \\
\text { da violência contra as mulheres } \\
\text { na América Latina e no Caribe. } \\
\text { O texto aborda questões sobre o } \\
\text { feminicídio, a violência física e } \\
\text { psicológica, a resposta } \\
\text { institucional e a prevenção. }\end{array}$ \\
\hline
\end{tabular}

Fonte: elaborado na pesquisa

No levantamento das produções de 2019, reconhece-se a necessidade de uma pesquisa futura mais ampla que analise a estratégia política do movimento em sua condição de ciberfeminismo, o que, a grosso modo, exige outras ferramentas teóricas inclusive das próprias perspectivas feministas; por outro lado, nos traz um exemplo dos novos caminhos de ativismo transnacional explorados pelas redes, cuja complexidade nos permite refletir até que ponto o ciberespaço tem servido de estratégia ou mesmo de arena política de diferentes atores das Relações Internacionais e de que modo vem sendo reaproapriado. Reforça-se a questão do acolhimento dos casos e também aponta a necessidade de se fortalecerem todas as instituições 
envolvidas no enfrentamento da violência, uma vez que, sem essa articulação intersetorial, a mulher acaba por ser novamente vitimizada ao não ter seus direitos garantidos. Os autores refletem sobre a problematização e análise de quais dinâmicas de poder separam as mulheres e colocam em disputa a (re)construção de um projeto feminista. Consideram o feminismo como possibilidade de politização da sociedade quando desnaturaliza as relações de poder que determinam a vida das mulheres na vida privada e pública, relações estas baseadas na subordinação compreendida como natural. Desnaturalizar a desigualdade e a submissão, e politizar a questão feminista são duas necessidades cruciais.

\section{Tendências para estudos na área da educação sexual}

Feitas estas reflexões, apresentamos algumas tendências que podem ser elencadas para a área da Educação Sexual no tocante à violência de gênero na América Latina e Caribe.

- Tendência 1. Empenhos governamentais, em políticas públicas: declarações, estudos visando elaboração de políticas, tanto em artigos, quanto em dossiês e obras como as da UNESCO, ONU e, principalmente, CEPAL. Dentre estas políticas, aparece no levantamento alguns trabalhos sobre a Lei Maria da Penha no Brasil. O foco, é, portanto, a violência contra mulheres e, raramente, se fala de adolescentes ou jovens ou um demarcador de idade, apenas mulheres, no âmbito geral.

- Tendência 2. Programas sociais em parcerias ou não com instituições internacionais como a UNESCO, a ONU, CEPAL, etc. Os programas de enfrentamento por movimentos sociais ou coletivos são mais expressivos. Está ausente qualquer ação de partidos políticos. As ações de pesquisas em universidades, geralmente, são conduzidas apenas por grupos de pesquisa ou pesquisas isoladas, havendo poucos Observatórios de Violência.

- Tendência 3. Estudos de caso, entrevistas, questionários, pesquisas acadêmicas, da iniciação científica a teses na pós-graduação que possuem como foco a violência de gênero, particularmente, contra mulheres, quase a totalidade dos estudos elencados e lidos são pouco direcionados para políticas públicas locais. Mas, o caminho inverso, de pesquisas da universidade serem patrocinadas ou encomendadas por importantes órgãos estão na maioria dos achados, nos indicando a possibilidade destas parcerias na América Latina e Caribe.

- Tendência 4. Vertentes teóricas para análise são muito raras. Está aqui uma lacuna ampla para as investigações em Educação Sexual. 
Como estas tendências podem se tornar programas de investigações na área da Educação Sexual para a América Latina e Caribe?

Em poucos destes trabalhos se vê o foco na Educação Sexual, tanto no caso da Educação Sexual ser considerada coadjutora para a erradicação da violência contra a mulher, quanto no caso de questões de violência contra a mulher e igualdade de gênero serem tópicos de propostas ou programas de Educação Sexual. Talvez, o principal investimento das pesquisas a partir das tendências apontadas é transpor, cada uma, para um projeto de Educação Sexual, seja para os espaços escolares ou não escolares.

No caso brasileiro, é importante se pensar na possibilidade de articulação, a partir da atual BNCC (Base Nacional Comum Curricular) entre o grande tema Violência contra a Mulher/Igualdade de Gênero e o conjunto de aprendizagens que os alunos devem desenvolver que estão sistematizadas, e são consideradas essenciais, na BNCC. No ensino superior, na formação inicial e continuada de professores, é importante o fomento de pesquisa e extensão, bem como de projetos de ensino, que coloquem o tema da violência de gênero como conhecimento a ser absorvidos pelos licenciandos(as) e licenciados(as). Importante pensar também, no caso dos mestrados profissionais, a elaboração de produtos educativos.

O desafio, mais amplo, de qualquer modo, para a Educação Sexual, é trazer para o currículo escolar e espaços não escolares a temática da violência de gênero no espectro da macrorregião da América Latina e Caribe.

\section{Conclusão}

A problemática desta pesquisa é respondida: as publicações indicam que os estudos sobre violência de gênero na América Latina e Caribe apresentam tendências à Educação Sexual quanto às pesquisas e investigações a serem feitas. A principal das tendências é a urgência de elaboração e construção de referenciais teóricos, estratégias didáticas e produção de materiais sobre a violência de gênero. Há um profícuo arcabouço estatístico e de dados reais, fenômenos sociais, históricos e científicos que podem se transformar em referenciais teóricos e ações que subsidiem os futuros trabalhos sobre a temática.

Especificar as violências é outra tendência: violência física, violência doméstica, violência psicológica, violência sexual, etc. Expandir para as outras categorias de gênero, além das mulheres - algo ausente nas produções dos últimos três anos - como, por exemplo, LGBT, a violência infantil, a violência adolescente, que, por exemplo, nos levam aos estudos sobre 
exploração/escravidão sexual infanto-juvenil. São instâncias que necessitam de muitos estudos na macrorregião latino-americana e caribenha.

A questão da violência de gênero na América Latina e Caribe deve ser assumida pela área da Educação Sexual como imperativo de currículo escolar, de currículo para coletivos nos movimentos sociais e partidos políticos. Não é porque temos um problema histórico e estrutural, político e "contaminador" que se deixará o assunto de lado ou apenas será tratado como algo dado, fixo. Com a perspectiva emancipatória em Educação Sexual, já consolidada na área, espera-se a ocorrência de denúncia, enfrentamento, políticas públicas e um currículo que eduque, empodere e transforme a realidade, por uma sociedade mais igualitária, mais diversa e mais respeitosa com mulheres, com LGBT, com crianças. Não é mais possível, com a gama de conhecimentos e políticas atuais, que se continuem as práticas de violência de gênero.

\section{REFERÊNCIAS}

ALVAREZ, S. E. Engajamentos Ambivalentes, Efeitos Paradoxais: Movimentos feminista e de mulheres na América Latina e/em/contra o desenvolvimento. Revista Feminismos, Bahia, n. 4, 2014.

ALVES, J. E. D.; CORRÊA, S. Igualdade e desigualdade de gênero no Brasil: um panorama preliminar 15 anos depois do Cairo. In: Brasil, 15 anos após a Conferência do Cairo. Campinas, SP: ABEP/UNFPA - United Nations Population Fund, 2009. p. 121-224.

APONTE SÁNCHES, E.; FEMENIAS, M. L. Articulaciones sobre la violencia contra las mujeres. La Plata: Universidad Nacional de La Plata, 2008.

ARNOLD, D. Y. (Comp.). Além do silêncio. As fronteiras de gênero nos Andes. La Paz: Biblioteca Andina, 1997.

BÁRCENA, A. ¿Qué estado para qué igualdad? Brasília: Secretaria Ejecutiva de la Comisión Económica para América Latina y el Caribe, 2010.

BRASIL. MINISTÉRIO DA SAÚDE. Saúde, migração, tráfico e violência contra mulheres: o que o SUS precisa saber. 1. ed. Brasília: Ministério da Saúde, 2013.

BUTLER, J. Bodies that matler: on the discursive limits of sex. Abingdon (England): Routledge, 1993.

CASTRO, R. RIQUER, F. La investigación sobre violencia contra las mujeres en América Latina: entre el empirismo ciego y la teoría sin datos. Rio de Janeiro: Cadernos de Saúde Pública, v. 19, n. 1, p. 135-146, 2003.

CEPAL. NACIONES UNIDAS. La autonomia de las mujeres em escenarios económicos cambiantes. Santiago, Chile: CEPAL, 2019. 
CEPAL. NACIONES UNIDAS. Panorama social da América Latina, 2019. Resumo executivo. Santiago, Chile: CEPAL, 2020.

COS-MONTIEL, F. Eliminar la violencia contra las mujeres en América Latina y el Caribe: objetivo imprescindible para el desarrollo sostenible, la igualdad y la paz. Madrid: Fundación Carolina, Análises Carolina, v. 19, p. 1-13, 2019.

DI PIERO, M. F. et al. Direitos humanos das mulheres: a luta contra a violência de gênero. São Carlos: Pedro \& João Editores, 2019.

GIANINI, R. A et al. A agenda sobre mulheres, paz e segurança no contexto latinoamericano: desafios e oportunidades. Artigo Estratégico 32. Rio de Janeiro: Instituto Igarapé - Rede de Mulheres, Paz e Segurança - Brasil, 2018.

GUAJARDO SOTO, G.; CENITAGOYA GARÍN, V. (Eds.). Feminicidio y suicio de mujeres por razones de género. Desafios y aprendizajes em la Cooperación Sur-Sur en America Latina y el Caribe. Santiago de Chile: Ediciones FLACSO, 2017.

LIMA, F. S.; COLOMBO, M. A. Pensamento descolonial e feminismo negro na América Latina. Belo Horizonte: Mentum, v. 14, n. 1, p. 181-201, 2019.

MARQUES, B. M. A atuação do movimento Ni Una Menos como rede (feminista) de ativismo transnacional na luta contra a violência de gênero na Argentina (2014-2016). Fronteira, Revista de Iniciação Científica em Relações Internacionais, v.18, n. 35, p. 6297, 2019.

MARQUES, R. M.; BARBOSA, E. C.; HUTZ, A. A situação da mulher na América Latina e no Caribe. Brasília: Temporalis, ano 10, n. 20, p. 197-220, 2010.

MEJÍA, M. C. et al. Factores de riesgo e indicadores de violencia de género en mujeres socias de bancos comunitarios en Chimborazo. Ecuador. Revista Espacios, v. 40, n. 32, p. 23-31, 2019.

MOGHADAM, V. (Org). The Oxford Handbook of Transnational Feminist Activism. Oxford: Ed. Oxford, 2015.

MONJE, F. R.; FOLLE, M. Z. Violencia de género contra las mujeres en América Latina: una reflexión crítica en torno a las agendas de género en la integración regional. Los casos de MERCOSUR y SICA. Revista Aportes para la Integración Latinoamericana, Año XXV, n. 41, p. 1-22, 2019.

NERI, F. S. Política de atención a mujeres em situación de violencia: um estúdio exploratório em Ciudad del Este y Foz de Yguazú. Revista MERCOSUL de Políticas Sociales, v. 3, p. 139-155, 2019.

OBSERVE. OBSERVATÓRIO DA LEI MARIA DA PENHA. Condições para aplicação da Lei 11.340/2006 (Lei Maria da Penha) nas Delegacias Especializadas de Atendimento à Mulher (DEAMS) e nos Juizados de Violência Doméstica e Familiar nas capitais e no Distrito Federal. Salvador: Observe-Observatório da Lei Maria da Penha, 2010. 
OMS. Estimativas globais e regionais da violência contra a mulher: prevalência e efeitos na saúde da violência por parceiro íntimo e violência sexual sem parceiro. Genebra: Organização Mundial da Saúde, 2013.

ONU MUJERES. El progreso de las mujeres en el mundo: en busca de la justicia. 20112012. New York: ONU, 2012.

ONU MULHERES. Entidade das Nações Unidas para a Igualdade de Gênero e o Empoderamento das Mulheres. Diretrizes Nacionais Feminicídio: investigar, processar e julgar. Com perspectiva de gênero as mortes violentas de mulheres. Secretaria de Políticas para Mulheres/Ministério da Mulher, da Igualdade Racial e dos Direitos Humanos: Brasília, 2016.

PEREIRA, A. C. Tolerância institucional à violência contra as mulheres. Brasília: CFEMEA, 2014.

SAFFIOTI, H. I. B. Gênero, patriarcado, violência. São Paulo: Fundação Perseu Abramo, 2004.

SAMPIERI, R. H.; COLLADO, C. F.; LUCIO, P. B. Metodologia de pesquisa. São Paulo: Mc Graw Hill do Brasil, 2006.

SAMPIERI, R. H.; COLLADO, C. F.; LUCIO, M. P. B. Metodologia da pesquisa. 5. ed. Porto Alegre: Artmed, 2006.

SCHWAB, K. The global gender gap report. World Economic Forum. Geneva, 2017.

SIKKINK, K.; KECK, M. E. Activists beyond borders: advocacy net works in international politics. Ithaca: Cornell University Press, 1998.

SILVA, C. R. Violência de gênero no Brasil e na América Latina: um enfoque psicanalítico a produção de conhecimento e perspectivas de enfrentamento. Doxa: Revista Brasileira de Psicologia e Educação, v. 20, n. 1, jan./jun. 2018. Disponível em:

https://periodicos.fclar.unesp.br/doxa/article/view/11284. Acesso em: 08 maio 2020.

SOARES, D. Z.; CHARLES, C. J. N.; CERQUEIRA, C. A. X. Feminicídio no Brasil: gênero de quem mata e de quem morre. In: ENANPEGE, 13., 2019, São Paulo. Anais [...]. São Paulo, 2 a 7 set. 2019.

TELES, M. A. A.; MELO, M. O que é violência contra a mulher. São Paulo: Brasiliense, 2002.

TONELLI, M. J. F.; BEIRAS, A.; RIED, J. Homens autores de violência contra mulheres: políticas públicas, desafios e intervenções possíveis na América Latina e Portugal.

Florianópolis: Revista de Ciências Humanas, v. 51, n. 1, p. 174-193, 2017.

WAISELFISZ, J. J. Mapa da violência 2015: homicídio de mulheres no Brasil. ONU Mulheres: Brasília, 2015.

YALEUMA, L. P.; VELOZ, S. P. Factores de riesgo e indicadores de violencia de género en 
mujeres socias de bancos comunitarios en Chimborazo. Ecuador. Revista Espacios, v. 40, n. 32, p. 23-31, 2019.

\section{Como referenciar este artigo}

MONTEIRO, Solange Aparecida de Souza; SILVA, Claudionor Renato; RIBEIRO, Paulo Rennes Marçal. Investigação da violência de gênero na América Latina e Caribe: pequena revisão da literatura (2017-2019). Revista on line de Política e Gestão Educacional, Araraquara, v. 24, n. 2, p. 649-667, maio/ago., 2020. e-ISSN:1519-9029. DOI: https://doi.org/10.22633/rpge.v24i2.13812

Submetido em: 20/10/2019

Revisões requeridas: $30 / 01 / 2020$

Aprovado em: 10/03/2020

Publicado em: 09/04/2020 